\section{5-Alpha-reductase deficiency in a Saudi 'girl'}

Sir,

5-Alpha-reductase deficiency is a rare but well recognised cause of familial male pseudohermaphroditism. So far, this disorder has been described in about 52 families from different parts of the world. ${ }^{1}$ Most of these patients are clustered in three kindreds in the Dominican Republic, ${ }^{2}$ Turkey, ${ }^{3}$ and New Guinea. ${ }^{4}$ There are a few reports of 5-alpha reductase deficiency in children of Arab ethnic background. ' To our knowledge there are only two reports of this disease from the Arabian Gulf region. ${ }^{1,5}$ We would like to report this disorder in a Saudi child.

A 14-year-old Saudi 'girl', born of consanguinous parents was referred to us for investigation for lack of breast development and primary amenorrhea. Mild clitoromegaly was observed in this child at birth but was not investigated further. She was operated twice elsewhere for bilateral inguinal masses at the age of six months and four years. She had normal milestones of development and had a female gender identity. During the six months prior to presentation, she was noted to have significant muscular development and showed interest in active sports. Family history was negative for any ambiguity in sexual development. On examination, she had a muscular build, pubic hair (Tanners P3) without any axillary or facial hair, or temporal recession of scalp hair. There was no sign of breast development. The external genitalia assessment showed a $3-\mathrm{cm}$ phallus, without urethral opening, partial posterior fusion of the urogenital sinus and lack of scrotalisation of labial folds. Sinogram confirmed a urethral opening close to the root of the phallus and a $1-\mathrm{cm}$ deep posterior pseudo-vagina. Gonads were not palpable. Ultrasound and computed tomography (CT) scan showed no uterus or adnexa and failed to locate any intraabnominal testes. Chromosome analysis revealed a $46 \mathrm{XY}$ pattern. Serum hormone profile showed luteinising hormone 15 IU/1 (normal 2-14 IU/1), follicle-stimulating hormone $9 \mathrm{IU} / 1$ (1-10 IU/1), testosterone 16.6 $\mathrm{nmol} / \mathrm{l}(10.4-34.3 \mathrm{nmol} / 1)$, dihydrotestosterone $0.36 \mathrm{nmol} / 1(1.3-1.96 \mathrm{nmol} / 1)$, testosterone/dihydrotestosterone ratio $46.2(<16)$, prolactin $888 \mathrm{pmol} / 1(44-932 \mathrm{pmol} / \mathrm{l})$, oestradiol $102 \mathrm{pmol} / 1$ (51-348 pmol/1), dehydroepiandosterone sulphate $4.8 \mu \mathrm{mol} / 1$ $(4.8-24.3 \mu \mathrm{mol} / 1)$, and cortisol $(08.00 \mathrm{~h})$ $386 \mathrm{nmol} / 1$ (137-687 nmol/1). All normal ranges are of an adult male.

With a $46 \mathrm{XY}$ chromosomal pattern, serum testosterone in the adult male range, a testosterone/dihydrotestosterone ratio of 46 and suggestive pubertal events, the diagnosis of 5-alpha-reductase deficiency was made in this child. To prevent further virilisation and changes in sexual behaviour, early laparotomy for removal of 'hidden testes' was advised. In spite of repeated counselling for six months, however, the family was undecided on the final sex of the child and did not give consent for surgical intervention. Later, she was lost to our follow-up. By reporting this patient, we stress the sig-

\begin{tabular}{|ll|}
\hline $\begin{array}{l}\text { 5-Alpha reductase } \\
\text { deficiency: }\end{array}$ \\
\hline features
\end{tabular}

nificance of investigation of any genital ambiguity, however mild it may be, in the neonatal period itself. This report also highlights the importance of evaluation for male pseudohermaphroditism in a 'female' child with inguinal masses or hernias. If proper attention had been given to these problems in this child with 5-alpha-reductase deficiency at an earlier stage, the psychological problems of late pubertal diagnosis could have been avoided.

$$
\begin{array}{r}
\text { JOHN PUNNOSE } \\
\text { KS MATHEW } \\
\text { HASSAN F AHMED } \\
\text { Department of Internal Medicine, } \\
\text { Al-Ain Hospital, } \\
\text { Al-Ain, United Arab Emirates }
\end{array}
$$

1 Wilson JD, Greffin JE, Russel DW. Steroid 5-alpha reductase deficiency. Endocrinol Rev 1993; 14: 577-93.

2 Thigpen AE, Davies DL, Gautier T, ImperatoMcGinley J, Russel DW. Molecular basis of steroid 5-alpha reductase deficiency in a large Dominican kindred. N Engl f Med 1992; 327: 1216-9.

3 Akgun S, Ertel NH, Imperato-McGinley J, Sayli BS, Shackleton C. Familial male pseudohermaphroditism due to 5-alpha reductase deficiency in a Turkish village. $A m \mathcal{F} M e d 1986 ; 81$ : 267-74.

4 Imperato-McGinley $\mathrm{J}$, Miller $\mathrm{M}$, Wilson JD, Peterson RE, Shackleton C, Gajdusek DC. A cluster of male pseudohermaphroditism with 5-alpha reductase deficiency in Papua, New 5-alpha reductase deficiency in Papua, 5 Chilango Mulaisha, Saoud A Taha, ImperatoMcGinley J. Male pseudohermaphroditism due to deficiency of steroid 5-alpha reductase enzyme. Saudi Med F 1990; 11: 71-3.

\section{Side-effects of coumarin}

Sir,

Coumarin, a drug acting on macrophages and lymphatic tissue and which is not licensed for use in the UK has been promoted as a treatment for oedematous states which are unassociated with hypoproteinaemia. ${ }^{1}$ The usual dosage is $200 \mathrm{mg}$ daily (Hamilton Pharmaceutical Pty Ltd, Adelaide, Australia). Toxicity is rare with elevation of liver enzymes in $0.37^{\circ}{ }_{0}$ of patients, probably as an idiosyncratic immune reaction. ${ }^{2}$ We here report a severe hepatic reaction to this drug.

A 49-year-old woman with chronic right leg lymphoedema (which had been comprehensively investigated with negative results) had been given coumarin $400 \mathrm{mg}$ daily for five months by a medical relative who had imported the drug from Australia. For many years she had used salbutamol and beclomethasone inhalers for asthma and frusemide and chlorthalidone for the oedema. She presented with a six-day history of malaise, sore throat and icterus for one day. She had been given penicillin $\mathrm{V}$ for four days prior to admission.

Investigation showed a bilirubin of 119 $\mu \mathrm{mol} / 1$ (normal less than $17 \mu \mathrm{mol} / 1$ ), an alanine transaminase of $5577 \mathrm{IU} / 1$ (normal less than $40 \mathrm{IU} / 1)$ and an alkaline phosphatase of $283 \mathrm{IU} / 1$ (normal less than $125 \mathrm{IU} / \mathrm{l}$ ). All tests for infectious agents including hepatitis A, B, C, and E, Epstein-Barr virus, cytomegalovirus and toxoplasmosis were negative. Coumarin was discontinued and all biochemical abnormalities had resolved five weeks later.

To our knowledge this is the only report of severe hepatotoxicity associated with coumarin. The highest alanine transaminase previously recorded is $960 \mathrm{IU} / \mathrm{l}^{2}$ and the Australian manufacturers of coumarin are aware of two other similar occurrences.

\begin{tabular}{|l|}
\hline Learning points \\
\hline - coumarin may cause severe \\
hepatitis \\
- international enquiries may have to \\
be made to obtain relevant \\
information regarding certain drugs \\
\hline
\end{tabular}

Two lessons emerge. Firstly, coumarin may occasionally cause severe hepatotoxicity. Secondly, there is a global market for therapeutic substances of all sorts and it may be necessary to make international enquiries to obtain relevant information regarding nonlicensed drugs.

LEWIS MORRISON PHILIP D WELSBY The City Hospital Edinburgh EH1O 5SB, UK

1 Casely-Smith JR, Casely-Smith JR. Highprotein oedemas and the benzopyrones. Sydney: Lippincott 1986; pp 176.

2 Cox D, O'Kennedy R, Thornes RD. The rarity of toxicity in patients treated with coumarin $(1,2-$ benzpyrone). Hum Toxicol 1989; 8: 501-6. 